\title{
КОРПУСНЫЙ АНАЛИЗ МОДАЛЬНЫХ СЛОВ СО ЗНАЧЕНИЕМ УВЕРЕННОСТИ В АНГЛИЙСКОМ ЯЗЫКЕ
}

\section{CORPUS ANALYSES OF MODAL WORDS WITH THE MEANING "ASSUREDNESS" IN ENGLISH LANGUAGE}

\section{T. Astakhova}

Summary: This article focuses on main features of modal words in English language. The purpose of this article is corpus analysis of collocates of modal words with the meaning "assuredness". The study is based on the material of the corpus of English language "British National Corpus". The results of the study indicate that all modal words have semantic peculiarities which are expressed in different meanings of collocates.

Keywords: modality, modal words, assuredness, corpus studies, English language.

\section{Введение}

K атегория модальности является многоаспектной, чем объясняется значительное количество точек зрения на нее в лингвистике. Основоположником теории модальности является В. В. Виноградов, который исследовал модальность в русском языке и отмечал, что при выражении мысли, чувства, побуждения формируются интонационные схемы предложения, а также выражаются синтаксические значения, образующие категорию модальности [6, с. 55-56].

Традиционно лингвисты выделяют объективную и субъективную модальность. Объективная модальность присутствует в любом высказывании и принимает участие в формировании предложения. Она выражает отношение сообщаемой информации к действительности в плане реальности и ирреальности. Субъективная модальность является необязательной составляющей высказывания и используется для экспликации отношения говорящего к высказыванию [5, с. 303].

А.В. Аверина придерживается другой точки зрения и утверждает, что субъективная модальность присутствует в любом предложении и, может быть, выражена разными способами - эксплицитно или имплицитно. Исследователь полагает, что модальное отношение включает в себя оценку говорящим степени реальности и вероятности того или иного факта [1, с. 14].

А.В. Зеленщиков отмечает, что модальность характеризует содержание предложения с точки зрения при-
Астахова Татьяна Николаевна

К.филол.н., дочент, Северный (Арктический) федеральный университет им. М.В. Ломоносова (г. Архангельск) t.astahova@narfu.ru

Аннотация: В данной статье рассматриваются основные характеристики модальных слов в английском языке. Целью работы является корпусный анализ коллокатов модальных слов со значением уверенности. Исследование осуществлялось с использованием корпуса английского языка British National Corpus. Результаты анализа показали, что все модальные слова имеют семантические особенности, которые выражаются в различии значений коллокатов.

Ключевые слова: модальность, модальные слова, уверенность, корпусные исследования, английский язык.

надлежности описываемой ситуации действительному миру [7, с. 73].

Ш. Балли рассматривает модальность в качестве модусной категории. Он отмечает, что предложения, содержащие модальные значения, состоят из двух частей - диктума и модуса, при этом модальное значение реализуется в модусной части предложения [3, с. 43-44].

А.В. Аверина классифицирует модальные значения, обобщив их в следующей классификации:

1. эпистемическая модальность (это значение предполагает выражение уверенности, неуверенности и сомнения в каком-либо факте действительности);

2. волюнтативная модальность (представляет собой модальность волеизъявления);

3. алетическая модальность (здесь имеет место выражение возможности и действительности);

4. деонтическая модальность (используется для выражения отношения сообщаемой информации к нормам права, морали, определённым обязательствам) [1, с. 21].

Модальность является функционально-семантической категорией, так как выражается на разных уровнях языка - фонетическом, морфологическом, лексическом, лексико-синтаксическом, синтаксическом, а также на уровне текста [7, с. 66].

В английском языке модальность выражается с помощью разнообразных языковых средств: модальных гла- 
голов, модальных слов, форм наклонения, интонации [2].

\section{$* * *$}

Модальные слова являются лексическим средством выражения модальности. Модальные слова не имеют единого внешнего признака с точки зрения формы, однако лингвисты предпринимают попытки их классификации. Так, Л.Н. Комарова отмечает, что большинство модальных слов произошли от наречий и совпадают с наречиями образа действия. Лингвист выделяет три группы модальных слов: простые, производные и составные. Например, модальное слово perhaps является простым. Производными модальными словами называются такие, которые имеют в составе суффикс -Іу. В качестве составного модального слова рассматривается слово maybe [8].

С точки зрения синтаксиса модальные слова выполняют в предложении функцию вводных членов предложения, при этом они могут относиться как к отдельному члену предложения, так и ко всему предложению. Модальное слово может занимать разные позиции - в начале, в середине или более редко - в конце предложения, когда оно имеет отношение ко всему предложению. Если модальное слово стоит между другими членами предложения, оно выражает наиболее сильную взаимосвязь с содержанием предложения, и наименьшую, если стоит в конце предложения. Модальное слово передаёт наиболее яркий оттенок значения, если занимает начальную позицию в предложении [9, с. 81].

С точки зрения семантики выделяют следующие группы модальных слов:

1. модальные слова, которые выражают оценку сообщаемой информации как реальной; к этой группе относятся модальные слова со значением уверенности: surely, assuredly, of course, certainly, indeed и со значением очевидности: apparently, evidently, obviously.

2. Модальные слова, которые выражают оценку сообщаемой информации как возможной, предполагаемой или ирреальной; к этой группе относятся модальные слова со значением вероятности: probably, possibly, со значением предположения: seemingly, supposedly, а также со значением сомнения: maybe, perhaps [4, с. 10-11]. Похожую классификацию без деления модальных слов на группы приводит М.И. Межерицкая [10, с. 284].

Как показал анализ изученной научной литературы, корпусные исследования модальных слов в английском языке весьма немногочисленны и начали появляться лишь в недавнее время [12; 13]. В связи с этим настоящее исследование является особо актуальным.
Целью данной статьи является корпусное исследование коллокатов (слов, окружающих лексические единицы справа и слева) модальных слов со значением уверенности. Исследование осуществлялось с использованием корпуса английского языка British National Corpus [11]. При выявлении коллокатов было задано значение 4 единицы справа и слева.

Так, в результате проведённого исследования были получены следующие результаты.

Так, для модального слова surely наиболее частотны следующие правые коллокаты: модальные глаголы must (с показателем частотности 207), ought (22), surely (19), intended (15), coincidence (10), deserves (9), realise (8), manage (8), preferable (7), harm (7), deserved (6). Приведем примеры из корпуса: 1) Was it just a coincidence that the names were so similar? Surely it must be. 2) But surely we ought to pause before we accept that ethics and law are irrelevant here. 3) Surely, surely, it makes much more sense. 4) The rations given to Parnaka were surely intended to support a large household, of a feudal type [11]. Отметим, что слово surely повторяется в разговорной речи.

Среди левых коллокатов модального слова surely наиболее частотными являются: must (показатель частотности 310), surely (19). Приведем пример из корпуca: 1) The answer to this question must surely be no [11]. Пример с удвоением данного модального слова уже был приведён выше.

Следовательно, в окружении модального surely преобладают лексические единицы со значением долженствования, намерения, наличия совпадения.

Рассмотрим коллокаты еще одного модального слова - assuredly. Среди правых коллокатов наиболее часто встречаются слова not (9), will (6), could (3), shall (2). Приведем примеры: 1) He would have chosen a museum or art gallery and assuredly not a university. 2) Assuredly some will prove more valuable, some less so, some unworkable. 3) But assuredly, the research could not take place without it [11]. Левые коллокаты в основном представлены следующими словами: will (8), most (7), assessed (2), world (2), go (2), например:

1. Past precedents indicate that conflict will assuredly arise.

2. ... Is most assuredly incorrect...

3. Such a contribution can not be assessed, but assuredly, the research could not take place without it [11].

Таким образом, модальное слово assuredly более часто выражает уверенность в действии или факте действительности в будущем, в наличии возможности, в отрицании чего-либо, а также часто сопровождается усилителем most. 
Модальная фраза of course имеет следующие правые коллокаты: exceptions (21), begs (6), converse (4) и другие. Например: 1) There are, of course, exceptions. 2) This, of course, begs the question of who is in the high risk group. 3) Of course, the converse can be said [11]. Наиболее частотны левые коллокаты unless (162), except (107), assuming (28), joking (10), discreetly (5). Приведём следующие предложения из корпуса:

1. Unless, of course, he did not want to be seen.

2. Except, of course, in our Eastern Region. Assuming, of course, that your story about Adam is the truth.

3. He was joking, of course [11].

Из этих результатов следует, что модальная фраза часто сопровождает факт уверенности говорящего в наличии условий, необходимости или просьбы, исключений, противоположностей, предположений, несерьезности чего-либо.

Модальное слово certainly встречается наиболее часто со следующими правыми коллокатами: true (213), helped (47), helps (19), intend (16), deserve (13), underestimate (9), worthwhile (9), preferable (8), plausible (7), feasible (7), например:

1. This is certainly true in the North-East.

2. Those games certainly helped to break the ice.

3. "It certainly helps," she said.

4. I most certainly do intend to stay on!

5. Liam Brady and his players certainly deserve something from the season [11]. Среди левых коллокатов следует выделить: almost (1489), debatable (5), conclusive (5).

Приведём примеры:

1. Well almost certainly it will be, I think.

2. Which of these are deliberate displays is sometimes debatable, but horses certainly act on them.

3. No conclusive evidence, certainly [11].

Как показал анализ материала, данное модальное слово выражает уверенность говорящего в истинности чего-либо, в эффективности помощи, в наличии намерений, заслуг, недооцененности чего-либо, наличие ряда положительных характеристик у объекта действительности, а также часто сопровождается значением с ограничительным значением almost.

Модальное слово indeed имеет следующие наибо- лее распространенные правые коллокаты: fortunate (12), doubtful (8), ironic (6). Приведём несколько примеров:

1. We are indeed fortunate.

2. Indeed it is doubtful if one group can even be called local.

3. It was indeed ironic that he should perish and his crew saved [11]. Наиболее частотными левыми коллокатами являются: nor (79), rare (52), seriously (36), praise (19), fortunate (13) и другие.

Рассмотрим несколько примеров:

1. Nor indeed is it necessary.

2. Pitched battles were rare; between kings they were very rare indeed.

3. He took the matter very seriously indeed.

4. Approbation from Sir Hubert Stanley is praise indeed [11].

Следовательно, модальное слово indeed в основном сопровождает различные признаки объектов действительности или действий, а также повторное отрицание.

\section{Зак^ючение}

Проведённый анализ показал, что модальные слова со значением уверенности в передаваемой информации имеют разные коллокаты. Так, модальное слово surely наиболее часто сопровождается лексическими единицами со значением долженствования (must, ought); assuredly часто выражает уверенность в действии или факте действительности в будущем (will, shall), в наличии возможности (could), а также в отрицании чего-ли6 (not). Модальная фраза of course преимущественно используется при выражении факта уверенности говорящего в наличии условий (unless), необходимости или просьбы (beg), исключений (exceptions, except), предположений (assuming), несерьезности чего-либо (joking). Модальное слово certainly часто используется для выражения уверенности в истинности того или иного факта (true), в эффективности помощи (helps, helped), в наличии намерений (intend), заслуг (deserve), недооцененности чего-либо (underestimate), сопровождается ограничителем almost. Модальное слово indeed наиболее часто встречается с признаками объектов (fortunate, doubtful, ironic, rare) или действий (seriously), а также с повторным отрицанием (nor).

\section{ЛИТЕРАТУРА}

1. Аверина А.В. Эпистемическая модальность как языковой феномен (на материале немецкого языка). - М.: Красанд, 2010. - 192 с.

2. Альмурзаева П.Х., Тимаева Ф.А. Лексические и лексико-грамматические средства выражения модальности в английском языке // Известия Чеченского государственного университета. - 2019. - № 2 (14). - C. 97-100. - URL: https://www.elibrary.ru/item.asp?id=38515347 (дата 0бращения: 27.12.2020).

3. Балли, Ш. Общая лингвистика и вопросы французского языка. - М.: Издательство иностранной литературы, 1955. -416 с.

4. Бачиева Р.И. К вопросу о классификации английских модальных слов // Materials of the XII international scientific and practical conference "Trends of modern 
science - 2016", May 30 - June 7, 2016. - Vol. 11: Pedagogical Sicences. - 2016. - C. 8-12. - URL: http://is.nkzu.kz/publishings/\%7BCB3F676F-551D-40F1B895-DEB09DD0B3B9\%7D.pdf\#page=8 (дата обращения: 27.12.2020).

5. Большой энциклопедический словарь. Языкознание / отв. ред. В.Н. Ярцева. - 2-е изд. - М.: Научное издательство «Большая Российская энциклопедия», 1998. -685 с.

6. Виноградов В.В. 0 категории модальности и модальных словах в русском языке // Труды Ин-та русского языка. - Т. 2. - М., 1950. - С. 38-79.

7. Зеленщиков А.В. Пропозиция и модальность. Изд. 2-е, доп. - М.: Книжный дом «Либроком», 2010. - 216 с.

8. Комарова Л.Н. Особенности и классификация модальных слов в английском языке // Наука, образование, общество: тенденции и перспективы развития : материалы II Междунар. науч.-практ. конф. (Чебоксары, 7 февр. 2016 г.) / редкол.: 0.Н. Широков [и др.] - Чебоксары: ЦНС «Интерактив плюс», 2016. C. 138-140. - URL: https://www.elibrary.ru/item.asp?id=25415923 (дата обращения: 27.12.2020).

9. Мамедова Т.И. Некоторые особенности морфологической структуры модальных слов английского языка // Велес. - 2019. - № 1-1 (67). - С. $78-82$.

10. Межерицкая М.И. Эпистемические значения и способы их выражения в английском и немецком языках // Вестник СПбГу. Язык и литература. - 2007. №1-II. - URL: https://cyberleninka.ru/article/n/epistemicheskie-znacheniya-i-sposoby-ih-vyrazheniya-v-angliyskom-i-nemetskom-yazykah-1 (дата обращения: 06.12.2020).

11. British National Corpus [Electronic resource]. - URL: https://www.english-corpora.org/bnc/ (date of access: 23.12.2020).

12. Pérez-Paredes P., Bueno-Alastuey M.C. A corpus-driven analysis of certainty stance adverbs: Obviously, really and actually in spoken native and learner English // Journal of Pragmatics. - 2019. - Vol. 140. - P. 22-32. - URL: https://doi.org/10.1016/j.pragma.2018.11.016 (date of access: 25.12.2020).

13. Szczyrbak M. Modal Adverbs of Certainty in EU Legal Discourse: A Parallel Corpus Approach // Aijmer K., Lewis D. (eds) Contrastive Analysis of Discourse-pragmatic Aspects of Linguistic Genres. Yearbook of Corpus Linguistics and Pragmatics. - Vol 5. - Springer, 2017. - URL: https://doi.org/10.1007/978-3-319-54556-1_5 (date of access: 25.12.2020).

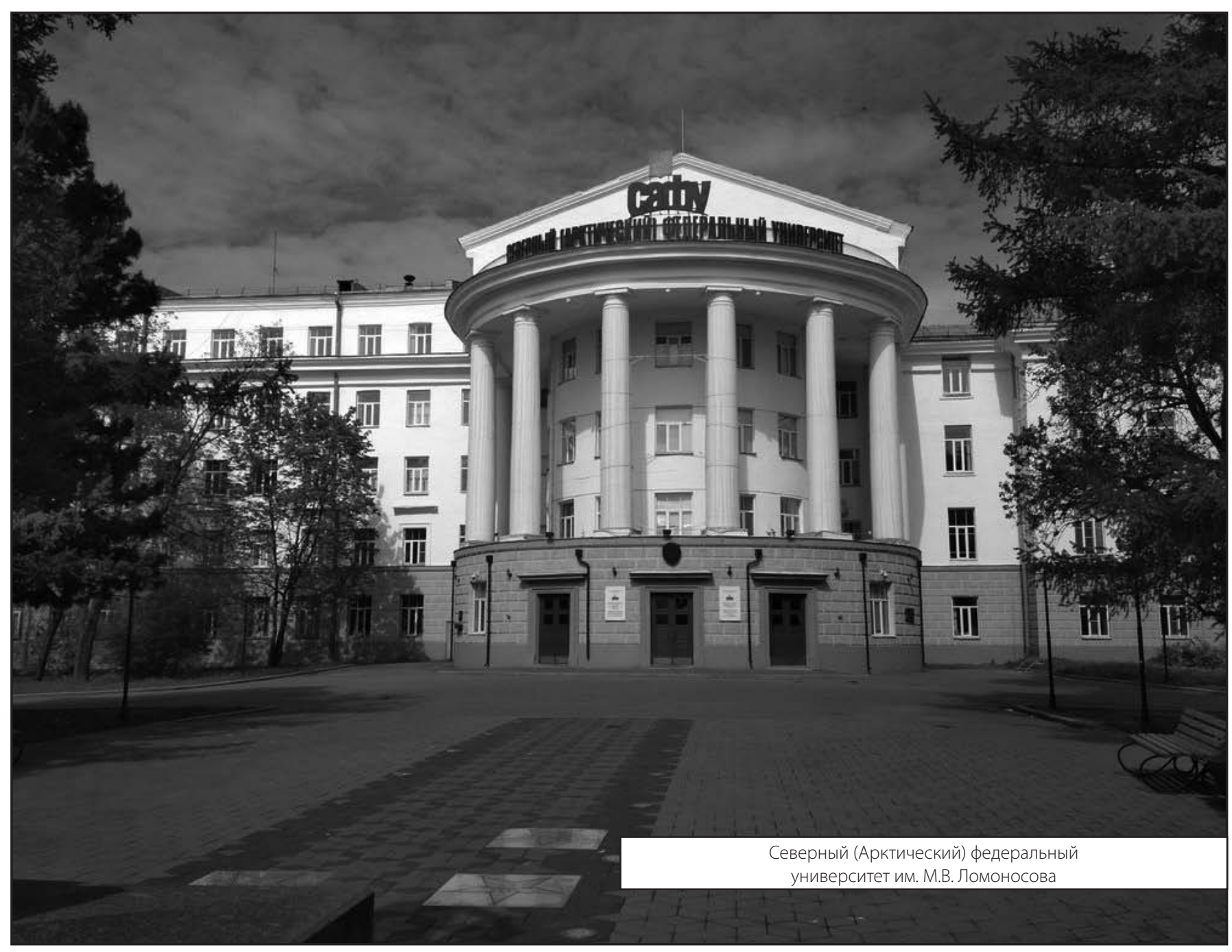

